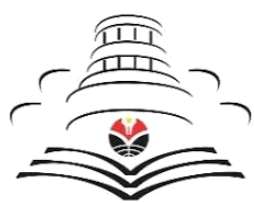

JURNAL UPI
Jurnal Kajian Bahasa, Sastra, dan Budaya Daerah serta Pengajarannya

Volume 10, No. 2, Bulan Oktober Tahun 2019, Hal. 161-170

p-2338-6193 (print) | e-2528-5904 (online)

Article URL: http://ejournal.upi.edu/index.php/lokabasa doi: 10.17509/jlb.v10i2

\title{
Aspek Sosial dalam Kumpulan Cerita Anak Ulin di Monumén Karya Tetty Hodijah
}

\author{
Kurnia Sari \\ SMP Edu Global Kota Bandung \\ kurniasr@gmail.com
}

\author{
Sejarah Artikel: Diterima (14 April 2019); Diperbaiki (28 Juni 2019); Disetujui (15 Agustus); \\ Pusblished (31 Oktober 2019) \\ Bagaimana mengutip artikel ini (dalam gaya APA): Sari, K. (2019). Aspek Sosialdalam Kumpulan \\ Cerita Anak Ulin di Monumén Karya Tetty Hodijah. Lokabasa 10(2). 161-170. doi: \\ $\underline{10.17509 / j l b . v 10 \mathrm{i} 2.21363}$
}

Abstrak: Penelitian ini dilatarbelakangi oleh kurangnya kesadasaran masyarakat mengapresiasi karya sastra yang banyak mengandung nilai-nilai sosial. Penelitian ini bertujuan untuk mendeskripsikan aspek sosial yang terkandung dalam kumpulan cerita anak Ulin di Monumén karya Tetti Hodijah. Metode yang digunakan dalam penelitian ini adalah metode deskriptif analisis, menggunakan langkahlangkah mengumpulkan data dari kumpulan carita anak Ulin di Monumén, menganalisis data yang terkumpul, dan mendeskripsikan data. Sumber data utama dari penelitian ini adalah buku kumpulan cerpen Ulin di Monumén karangan Tetti Hodijah. Data yang diperoleh berupa catatan hasil telaah studi pustaka. Hasil penelitian ini menemukan 3 aspek sosial yaitu aspek sosial agama, aspek sosial ekonomi, dan aspek sosial pendidikan. Dari aspek sosial agama, ditemukan 3 unsur yang berkaitan dengan keagamaan yaitu percaya kepada Allah Swt, menjalankan perintah Allah Swt, serta ikhlas dan bersyukur kepada Allah Swt. Dari aspek sosial ekonomi ditemukan 3 tingkatan ekonomi yaitu ekonomi kalangan atas, dan ekonomi kalangan menegah. Dari aspék sosial pendidikan ditemukannya 6 unsur aspék pendidikan yaitu tatakrama, rasa saling menghargai, cinta tanah air, jauh dari iri dan dengki, dan belajar menuruti aturan yang berlaku di masyarakat.

Kata Kunci: aspek sosial agama, aspek sosial ekonomi, dan aspek sosial pendidikan.

\section{Social Aspect in a Collection Tale of Ulin di Monumén by Tetty Hodijah}

Abstract: This research is motivated by the lack of awareness of the community to appreciate literary works that contain many social values. This study aims to describe the social aspects contained in the collection of Ulin children's stories at Monumén by Hodijah Tetti. The method used in this study is a descriptive analysis method, using steps to collect data from a collection of children Ulin in Monumén, analyze the data collected, and describe the data. The main data source of this research is the book collection of Ulin's short stories in Monumén by Tetti Hodijah. The data obtained is in the form of notes on the results of a literature study. The results of this study found 3 social aspects, namely social aspects of religion, socio-economic aspects, and social aspects of education. From the social aspect of religion, 3 elements related to religion were found, namely believing in Allah Swt, carrying out the commands of Allah Swt, and being sincere and thankful to Allah Swt. From the socio-economic aspect, it was found 3 levels of economy, namely the upper class economy, and middle class economy. From the socio-educational aspect, six elements of education were found, namely manners, mutual respect, love for the country, far from being jealous and envious, and learning to obey the rules that apply in society.

Keywords: social aspects of religion, socio-economic aspects, and social aspects of education. 


\section{PENDAHULUAN}

Gambaran mengenai kehidupan manusia dan lingkungan sekitarnya dihadirkan melalui karya sastra. Karya sastra merupakan bagian penting yang tidak terlepas dari kehidupan anak-anak, juga lekat dengan kehidupan sosial di masyarakat. Kurangnya pemahaman masyarakat terhadap karya sastra, yang sebenarnya mempunyai banyak aspek untuk digali. Aspek sosial dirasa kurang tergali dalam sastra anak, padahal bisa menjadi media di dalam pendidikan, dilihat dari beberapa aspek, khususnya bacaan untuk anak-anak.

Hal ini sesuai dengan pernyataan Sarumpaet (2009, hlm. 12) yang menyebutkan bahwa sastra anak di samping sifatnya hiburan, juga alat untuk menyampaikan maksud dan tujuan kepada pembaca agar bisa memahami beberapa aspek yang terkandung di dalamnya. Menurut Hasanuddin (2015, hlm. 2) sastra anak merupakan karya sastra yang "cocok" untuk dibaca, didengar, atau dikonsumsi oleh anak-anak. Kata "cocok" disini memberi gambaran tentang sastra anak yang mempunyai syarat khusus yaitu sesuai atau tidaknya teks tersebut untuk bacaan anak-anak. Dengan demikian sastra anak dapat membantu membiasakan kegiatan literasi, yang menurut Suherman (2019, hlm. 267) dapat dikategorikan sebagai kegiatan literasi dasar.

Isi sastra anak pun merupakan cerita atau pesan yang dianggap sesuai dengan tingkat emosional dan intelektual anak. Sastra anak tidak cukup ditulis dan diterbitkan saja, melainkan perlu bimbingan dari orang tua yang membacakannya. Dengan cara itu, amanat yang terkandung di dalamnya akan tersampaikan dan difahami oleh anak, sehingga anak-anak bisa memahami mana perilaku yang patut dicontoh dan mana yang tidak boleh ditiru.

Cerita pendek menjadi salah satu bahan bacaan yang menarik untuk anakanak. Kandungan dalam cerita pendek mengandung kenyataan yang menyangkutpautkan kehidupan sehari-hari. Dengan begitu, cerpen tidak lepas dari berbagai aspék sosial yang terkandung di dalamnya.

Kumpulan cerita anak Ulin di Monumén (seterusnya disingkat $U d M$ ) tentunya mempunyai masalah-masalah sosial yang harus ditelusuri. Dengan begitu, kumpulan cerita anak $U d M$ jadi objek yang akan dianalisis aspek sosialnya dengan menggunakan teori sosial sastra.

Sosial sastra menurut Anwar, (2012, hlm. 1) adalah teori yang pembahasannya lebih komprehensif, bagaimana karya sastra yang dipandang dari berbagai aspek sosial serta bagaimana masyarakat yang selalu mempengaruhi proses terciptanya karya sastra. Jadi, aspek sosial sangat erat kaitannya dengan karya sastr, sebab dalam karya sastra tergambar beberapa aspek sosial.

Berdasarkan hal di atas, analisis aspek sosial dari kumpulan cerita anak bisa menjadi salah satu media pembelajaran dalam kehidupan anak-anak, terutama di dunia pendidikan.

\section{METODE}

Penelitian ini termasuk kajian kualitatif, yaitu penelitian yang sumber datanya merupakan kata-kata dalam bentuk lisan atau tulisan. Hal tersebut diteliti dan dianalisis lebih dalam agar mendapatkan sebuah makna (Moleong dalam Arikunto, 2013, hlm. 22).

Metode yang digunakan dalam penelitian ini yaitu deskriptif, yang mempunyai tujuan untuk mendeskripsikan, maksudnya membuat gambaran, lukisan secara sistematis, faktual dan akurat mengenai data, sifat-sifat, serta hubungan fenomena-fenomena yang diteliti (Djajasudarma, 2010, hlm. 9).

Sumber data yang digunakan yaitu kumpulan cerpen Ulin di Monumén karya Tetty Hodijah. Adapun teknik yang digunakan adalah telaah pustaka yang seterusnya dianalisis dengan cara membaca sumber data secara utuh. 
HASIL DAN PEMBAHASAN

(UdM, hlm. 10)

\section{Aspek Sosial}

Aspek sosial adalah kenyataan yang berkaitan dengan kehidupan sehari-hari, dilihat dari keadaan, kejadian, dan proses yang berlangsung di masyarakat.

Hal ini sejalan dengan konsep teori sastra yang mengaitkan sastra dan masyarakat, pertama ada dan dianggap konkret oleh Platopada taun 427-347 SM dalam konteks pemikirannya mengenai Negara, sebelum asumsinya mengatakan bahwa sastra adalah hasil refleksi dari masyarakat (Anwar, 2010, hlm.2).

Aspek sosial menurut Anwar (2012, hlm. 12) adalah pembahasan yang dikaitkan dengan karya sastra, sebab karya sastra terutama cerpen ttidak bisa lepas dari aspek sosial masyarakat.

Kehidupan bermasyarakat yang tergambar pada karya sastra anak juga berhubungan dengan bagaimana pendidikan yang harus selalu dihubungkan agar karya sastra tersebut bermanfaat. Nilai sosial adalah nilai-nilai kolektif yang dianut oleh masyarakat kebanyakan.

\section{Aspek Sosial Agama}

Aspék sosial agama merupakan salah satu dari pendidikan karakter dalam sastra anak. Menurut Hasanuddin (2015, hlm. 18) iman dan taqwa jadi dasar dalam aspek pendidikan karakter sastra anak. Indikator perilaku yang bias dinilai dalam aspek sosial agama adalah percaya kepada Allah Swt, menjalankan perintah Allah Swt, serta ikhlas dan bersyukur kepada Allah Swt. Aspek sosial agama terdapat dalam cerita "Paguneman", "Surat keur Pusi", "Usum Halodo Panjang", dan "Nganjang ka Sakola Luar Biasa”.

\section{Carpon "Paguneman"}

"Wanci janari dunungan gugah, teras abdas, cong solat."

"waktu dini hari jurgan terbangun, lalu mengambil air wudhu, dan menunaikan sholat."
Dari sempalan cerita di atas, ada nya aspek sosial agama yang termasuk kedalam indikator aspek agama yaituh menjalankan perintah Allah SWT. terlihat pada sempalan di atas yang menggambarkan ketaatan seorang muslim dalam menjalankan ibadahnya.

"Ngeusian mah ngeusian wé, nu penting urang geus niat hadé tur iklas."

"silahkan kalo mau di isi, yang terpenting kita sudah mempunyai niat baik dan ikhlas."

(UdM, hlm. 10)

Dari sempalan cerita di atas, adanya aspek sosial agama yang menggambarkan bagai mana kita sebagai seorang muslim belajar ikhlas dalam hal memberi sodakoh kepada mesjid walaupun sudah sering terjadi hilangnya kotak amal di masjid. Hal ini tergolong kedalam indikator kepada Allah SWT bahwa kita mempunyai niat yang baik, ikhlas, dan ridho

Carpon "Surat keur Pusi”

"Kuring ngarénghap panjang. Halis kerung. Cariosan Mamah hnteu lepat, tapi ieu haté asa hésé narima, sabab Pusi paéhna alatan katabrak. Tapi najan kuring ceurik lolongséran, Pusi pamohalan bisa kapuluk deui, hiji-hijina jalan, kuring kudu pasrah narima kanyataan, Pusi ninggalkeun kuring keur sapapanjangna."

"saya menarik nafas panjang. Dan menaikan halis. Yang di ceritakan mamah tidak salah, tapi hati ini tidak mau menerima, sebab Pusi mati tertabrak. Walupun saya menangis berdarah-darah, pusi tidak akan hidup lagi, satu-satunya jalan, saya harus ikhlas menerima ke matian puisi.'

(UdM, hlm. 14) 
Kutipan cerpen "Surat keur Pusi"di atas menunjukan aspek sosial agama yang berusaha untuk mengikhlaskan binatang kesayangannya yang sudah mati dan Ibunya menjelaskan bahwa kita pun manusia yang suatu saat pasti akan bertemu dengan ajal.

Carpon "Usum Halodo Panjang”

"Can gé beubeunangan, hawar-hawar sora adzan. Buru-buru nyampeurkeun séké, rék ngadon wudu."

"Belum juga menghasilkan, sudah terdengar suara adzan. Lalu bergegas ke tempat wudhu."

(UdM, hlm. 19)

"Tara kungsi dikomando, geus wanci kieu mah sok hideng ngarumpul deui dina batu datar parantina. Ngaradon solat babarengan."

"sebelum diperintah, jika sudah waktunya akan berkumpul di batu datar itu. Shalat berjamaah. Selesai shalat Ashar, lalu pulang ke rumah Bersama-sama di waktu menjelang magrib."

(UdM, hlm. 20)

Dua kutipan cerpen "Usum Halodo Panjang"menunjukan aspek sosial yang berkaitan dengan agama yang menggambarkan ketika anak-anak sedang asik bermain, tetapi mereka tidak lupa melakukan kewajibannya sebagai umat muslim, dan menjalankan shalat berjamah. Kemudian mereka lekas pulang bersamasama setelah melaksanakan shalat.

\section{Carpon "Di Langit Béntang Baranang"}

"Di luhur langit lénglang taya hahalang, dipasieup béntang mani baranang. Saréréa cruk crek muji kaagungan $\mathrm{Nu}$ Maha Kawasa, nu parantos nyiptakeun alam nu sakieu éndahna."
"Di atas langit tidak ada yang menghalangi, bintang begitu bertaburan. Semuanya lalu bersyukuri kepada Tuhan YME, apa yang telah dilihat begitu indahnya."

(UdM, hlm. 55)

Dari sempalan cerita di atas, menggambarkan adanya aspek sosial agama yang tergolong kedalam indikator bersyukur kepada Allah SWT.

Carpon "Nganjang ka Sakola"

"Ibu ngahaja ngajak hidep ka SLB ieu, sangkan hidep sukuran ka Allah, nu tos nyiptakeun hidep kalayan sampurna, boh méntal boh fisik. Ciri jalma nu sukuran téh nyaéta nu mampu ngamangpaatkeun poténsi nu aya dina dirima kalayan daria, nepi ka jadi jalma nu gedé mangpaatna pikeun dirina jeung nu lian. Piraku éléh ku dulur-dulur hidep nu nandangan disabilitas."

"Ibu sengaja mengajak kalian ke SLB, supaya kalian bersyukur kepada Allah SWT, yang menciptakan kalian dengan sempurna baik secara mental maupun fisik. Ciri orang yang bersyukur adalah yang mampu memanfaatkan otensi yang ada dalam dirinya, sehingga menjadi manusa yang bermanfaat untuk dirinya dan orang lain. Jangan kalah dengan sodara-sodara kalian yang menyandang disabilitas."

(UdM, hlm. 62)

Dari sempalan cerita di atas, menggambarkan adanya aspek sosial agama yang tergolong kedalam indikator bersyukur kepada Allah SWT.

\section{Aspek Sosial Ekonomi}

Aspek sosial ekonomi merupakan aspek yang berkaitan dengan kehidupan sosial pelaku dalam cerita. Aspek sosial ekonimi jadi ruang untuk mewadahi kenyataan sosial khususnya yang berkaitan dengan kelas sosial masyarakat. Budaya 
menjadi inspirasi pengarang untuk menciptakna karya yang biasanya membawa kedudukan, umpamanya raja dan budaknya. Asepk sosial ekonomi juga memperlihatkan adanya kelas sosial atas dan bawah(Anwar, 2010, hlm. 51). Aspék sosial ekonomidalam penelitian ini terbagi menjadi dua yaitu keadaan sosial ekonomi kalangan menengah dan ekonomi mengengah ke atas. Terdapat dalam cerita "Kanyaah Mamah", "Sang Raja", dan "Si Centil Uky".

\section{Carpon "Kanyaah Mamah”}

"Kadieunakeun bekel sakola digédéan, angger sok dicéngcéléngankeun, sanajan Mamah katingal siga seueur artos ogé. Mamah sering méséran acuk, boh keur kuring, boh kanggo Papah, atanapi kanggo Mamah. Hiji waktu mamah mulih, pananganana rébo nyandak hasil."

"Semakin kesini uang jajan kesekolah ditambah tapi tetap ditabung, walau pun mamah terliha seperti banyak uang, mamah sering membelikan baju untuk ku dan papah atau pun untuk mamah. Satu waktu mamah pulang membawa banyak hasil.”

(UdM, hlm. 23)

Dari sempalan cerita di atas, menggabrakan keadaan sosial ekonomi kalangan menengah, karena harus menabung dahulu untuk membeli sepeda baru.

\section{Carpon "Sang Raja"}

"Saban poé kahirupan kuring teu weléh lancar tur hipu. Taya kahayang nu dipungpang, taya paménta nu teu ditedunan. Ménta motor gé buru-buru dipangmeulikeun. Tara ngarasa kakurangan keur duit jajan. Pantes rék kaimpungan ku babaturan ogé, da puguh kuring mah sok resep ngajajanan babaturan. Mun kuring ngambek sok buru- buru ménta dihampura, da sieun isukan teu dijajanan deui meureun."

"Setiap hari kehidupanku selalu lancar. Tidak ada keinginan yang tidak boleh, tidak ada keinginan yang tidak dipenuhi. Meminta motor pun cepat-cepat dibelikan. Tidak merasa kurang uang untuk jajan. Pantas saja banyak teman, sebab aku selalu menjajani teman-teman."

(UdM, hlm. 29)

"Kungsi aya babaturan nu kumawani ka kuring. Buru-buru ménta duit ka Ema, tuluy mayar balad-balad sangkan nyerang babaturan nu galak téa, jadi wéh ngéléhan. Nepi ka ayeuna tara wanieun deui galak ka kuring."

"Pernah ada teman yang berani kepada ku. Lalau memeinta uang kepada Ema, lalu membayar teman-teman untuk membalas. Setelh itu, sampai sekarang tidak pernah mau lagi memarahi aku lagi.",

(UdM, hlm. 29)

Dari dua kutipan cerpen "Sang Raja", tergambar bahwa kehidupanya yang mewah menjadikannya anak yang mengandalkan segalanya dengan uang. Tidak ada permintaan yang tidak pernah dipenuhi. Termasuk caranya mencari teman

\section{Carpon "Si Centil Uky"}

"Sabar, Geulis, Mamah nuju nyéngcéléngan heula. Pangaos sapéda weuteuh téh pangaosna sami sareng gaji Papa sasasiheun. Upami gajih Papa sadayana dipésérkeun sapéda, atuh moal aya kanggo emam sareng jajan Tita."

"Sabar, Cantik, Mama sedang menabung. Harga sepeda baru itu harganya sama dengan gaji Papa satu bulan. Jika gaji Papa dibelikan sepeda, maka tidak ada untuk makan."

(UdM, hlm. 32) 
Dari kutipan cerpen "Si Centil Uky"di atas, menjelaskan bahwa keinginan Tita tidak bisa langsung dipenuhi, karena harga sepeda baru sangat mahal, sama dengan gaji Ayah Tita selama satu bulan. Perekonomian keluarnya, menuntut Ibu Tita untuk menabung terlebih dahulu karena jika keinginan Tita langsung dilaksanakan, maka Ibu Tita akan kesulitan untuk memikirkan biaya makan.

Carpon "Di Langit Béntang Baranang" "Sabar wé atuh Téh. Papah sareng Mamah sanés niat ngabohong pastina ogé, pan tos dijelaskeun alesanana. Piknik teu cios téh kumargi Papah kénging tugas ngadadak ti kantorna, nu teu tiasa diwakilkeun ka nu sanés. Mamah ogé kapareng tokona nuju maréma, seueur nu balanja. Toko pakéan téa, usum liburan kieu mah seueur nu ngadon ti luar kota."

"Sabar Teteh, papah dan mamah bukan berniat untuk berbohong, tetapi kan sudah dijelaskan alasannya. Piknik tidak jadi karena papah mendapat tugas mendadak dari kantornya, yang tidak bisa di wakilkan oleh orang lain. Mamah pun kebetulan tokonya sedang ramai, banyak yang berbelanja. Jika musim libur toko baju mamah selalu di penuhi pembeli dari luar kota."

(UdM, hlm. 50)

Dari kutipan cerita di atas, menggambarkan keadaan sosial ekonomi kalangan menengah ke atas. Dilihat dari Papah Tita yang bekerja di kantor, dan Ibu Tita yang mempunyai toko baju.

Carpon "Katempuhan"

"Ieu artosna," pokna ngaluarkeun duit tina dompétna, lambaran ratusan rébu.

"Ini uangnya,"ujarnya mengeluarkan uang dari dompet lembaran ratusan ribu.

(UdM, hlm. 64)

"Andi lumpat muru kamar indungna, gap kana dompét, ngadudut sababaraha lambar warna beureum, teu lila ka luar deui, song dibayarkeun."
"Andi berlali menuju kamar ibu nya, lalu mengambil beberapa lembar uang warna merah dari dompet, dan tak lama keluar lagi, untuk membayarkannya."

(UdM, hlm. 65)

Dari kutipan cerita di atas tergambar bahwa keadaan keluarga andi termasuk kedalam golongan sosial ekonomi menengah ke atas.

\section{Aspek Sosial Pendidikan}

Aspek sosial pendidikan yang ada dalam sastra anak sangatlah penting sabab menyampaikan norma-norma yang harus diajarkan kepada anak-anak melewati ceritanya. Di dalam isi cerita tidak hanya meyampaikan hal yang berkaitan dengan pendidikan saja, tettapi selain itu sudah menjadi emosional anak, intelegensi, dan menimbulan rasa empati setelah membacanya (Mulyana, 2011, hlm. 71).

Selain itu menurut Suherman \& Nugraha (2019, hlm. 347)buku atau bahan bacaan anak yang penuh dengan pesan moral dijadikan tuntunan dalam kehidupan anak sehari-hari. Yang dituangkan dalam alur cerita dan memperlihatkan beberpa karakter.

Siswa SD yang sudah mempuyai kemampuan berpikir abstrak, dalam hartian menggunakan nalar atau (reasoning), membereskan beberapa permasalahan (problem solving), dan melakukan tindakan.Dalam hal ini, usia anak SD sedang berada dalam fase meningkatkan daya ingat (memory). Dalam fase ini mempengaruhi peningkatan aspek sosial individual (Mulyana, 2011, hlm. 66).

MenurutKosasih (2013, hlm. 227) Secara umum anak-anak yang dilibatkan pada karya sastra menjadi hal yang terbilang sangat baik, sebab akan mendapatkan banyak manfaat setelah membaca cerita fiksi. Walaupun fiksi tetapi dalam sastra anak banyak hal-hal positif yang disampaikan oleh pengarang kepada pembaca untuk anak-anak. 
Aspek sosial yangberkaitan dengan pendidikan mempunyai beberapa unsur yaitu tatakrama atau rasa hormat, keluarga yang menjadi titk utama di dunia pendidikan, rasa saling menghargai, tidak sirik dan dengki, cinta tanah air, dan belajar mematuhi peraturan yang berlaku di masyarakat.Terdapat dalam cerita "Usum Halodo Panjang", "Kanyaah Mamah" "Si Centil Uky", dan "Sang Raja".

Carpon "Usum Halodo Panjang"

"Maaah, Idang mios.”

"Maaah, Idang berangkat"

(UdM, hlm. 15)

Kutipan cerpen di atas menunjukan bahwa nilai Pendidikan tatakrama di keluarga sangat baik. Sebab keluarga adalah Pendidikan pertama bagi anak sebelum Pendidikan di sekolah.

Carpon "Kanyaah Mamah"

"Kasono ka Mamah teu leungit-leungit, najan datang deui Mamah anyar, kapeurih teu sing kaubaran. Mamah anyar mah tara ngadongéng méméh bobo, tara ngajarkeun tembang."

"Rindu pada mamah tidak henti-hentinya, walaupun datang lagi mama baru, rasa sakit tidak pernah terobati. Mama baru tidak pernah mendongeng sebelum tidur, tidak diajarkan tembang. "

(UdM, hlm. 24)

Dari kutipan cerpen "Kayaah Mamah" tergambar bahwa rasa saying Ibu kandung itu tidak akan pernah tergantikan. Tidak seperti Ibu baru yang tidak mengajarkan beberapa hal yang biasanya diajarkan oleh Ibu kandung. Itulah pentingnya Pendidikan pada anak-anak. Bagaimana pun Pendidikan dari usia dini sangat penting terutama dari orang tuanya sendiri.
Carpon "Sang Raja"

"Peryogi kauninga ku Bapa sareng Ibu, ieu murangkalih teu acan manjing nganggo kendaraan bermotor, margi yuswana nembé sapuluh taun."

"Perlu diketahui oleh bapa dan ibu, anak ini belum waktunya mengendarai kendaraan bermotor, karena umur nya baru sepulu tahun."

(UdM, hlm. 30)

Dalam kutipan cerita di atas, tergambar bahwa adanya aspek sosial pendidikan yang mengajarkan bahwa anak usia dibawah umur, menurut peraturan yang berlaku tidak boleh mengendarai kendaraan bermotor, dan tidak boleh melanggarnya.

"Hiji hal nu kedah dicatet ku Bapa sareng Ibu, upami ngogo budak kaleuleuwihi, éta budak bakal bedegong, adigung, sombong, gedé hulu, tur hésé diwarah."

"Satu hal yang haru dicatat oleh Bapa dan Ibu, jika anak dimanja berlebihan, maka Ia akan menjadi anak yang sulit untuk diberi tahu, sombong, dan sulit untuk diajarkannya."

(UdM, hlm. 30)

Berdasarkan kutipan cerpen "Sang Raja" di atas, dijelaskan bahwa mendidik anak itu harus sewajarnya. Karena bagaimanapun kondisi keluarga, utamanya dalam perekonomian sangat mumpuni, tetapi tidak menutup kemungkinan anak itu akan menjadi anak yang sangat manja dan susah diatur. Jadi, mendidik anak harus sewajarnya, dan sesuai dengan norma yang telah berlaku. Sekali pun Ia mempunyai segalanya, tetapi harus dibatasi tidak boleh berlebihan. Karena dampaknya akan menjadi buruk. 
Carpon "Si centil Uky"

"Ti mimiti poé ieu kuring sosobatan deui jeung Uky. Kuring reueus boga sobat manéhna, geulis, ramah, cerdas, resep tutulung. Éstuning tuladaneun. Dicatet dina haté, moal deui-deui ngéwa ka sasama, komo ka nu jadi sobat mah, geus karasa akibatna."

"Mulai hari ini aku bersahabat lagi dengan Uky. Aku bangga mempunyai teman sepertia dia. Cantik, ramah, cerdas, suka menolong. Sangat tauladan. Dicacat di dalam hati, tidak akan lagi benci pada sesame, apalagi sudah tau akibatnya."

(UdM, hlm. 35)

Pada kutipan cerpen "Si Centil Uky”tergambar bahwa tidak boleh iri pada sahabat, terutama iri karena sahabat kita memiliki kelebihan yang tidak kita miliki. Seharusnya bisa saling melengkapi bukan malah dijauhi dan dibenci.

\section{Carpon "Ulin di Monumén"}

"Sanggeus hidep ulin di monumén, mudah-mudahan jadi leuwih sumanget diajar, sangkan hiji waktu hidep mampu bajoang, sarta ngamumulé tur miara lemah cai kalayan hadé. Tina pilem tadi, kasaksén ku hidep, kumaha perjuangan nini aki urang enggoning ngarebut kamerdékaan ti para penjajah, apanan sakitu hésé jeung capéna. Sasat ku amayatakna getih-getih para pahlawan nu tos bajoang tanpa pamrih. Kaulinan tadi, mangrupa hiji gambaran, yén enggoning ngudag harepan jeung cita-cita téh urang kudu bajoang kalayan sumanget. Komo deui mun nu dicita-citakeun ku urang téh hayang ngéléhkeun musuh pikeun ngabéla bebeneran, lian ti kudu boga modal sumanget, kudu diémbohan ku kawani jeung kaludeung."

"setelah kalian bermain di monumen, mudah-mudahan jadi lebih giat belajar, hingga pada satu hari nanti kalian akan menjadi mandiri, serta bisa menjaga dan memelihara martabat bangsa dengan sepenuh hati. Bisa terlihatdari film yang kita tonton tadi, bagaimana perjuangan orang-orang terdahulu untuk merebut kemerdekaan dari penjajah, sampai tumpah darah penghabisan. Permainan yang tadi merupakan salah satu gambaran, bahwa menggapai cita-cita harus mempunyai semangat. Apalagi jika kita memeiliki keingina mengalahkan musuh untuk membela kebenaran, selain mempunyai semangat harus juga memeiliki keberanian."

(UdM, hlm. 45)

Dalam kutipan cerita di ats, tergambar bahwa kita harus mencintai negri kita dan menghargai perjuangan para pahlawan. Selain itu, kita harus lebih bersemangat untuk menggapai cita-cita dan berani membela kebenaran.

Carpon "Di Langit Béntang Baranang”

"Linda janji dina haténa, moal deui-deui ngaraheutan Mamah sareng ka Papah, ayeuna mah karasa pisan, geuning aranjeunna téh sakitu nyaraaheunana,"

"Dalam hati nya Linda berjanji tidak aka menyakiti mamah dan papah, sekarang baru terasa mereka begitu sayang padanya."

(UdM, hlm. 56)

Dari kutipan cerita di atas, adanya aspek sosial pendidikan yang mengajarkan bahwa kita tetap harus hormat kepada orang tua kita. Jangan sampai melukai hatinya.

Carpon "Nganjang ka Sakola Luar Biasa"

"Ibu ngawawadian, boh di jalan boh di ditu, omat ulah caliweura, komo nyengseurikeun batur mah,..." 
"Ibu mewanti-wanti, jika dijalan atau disana, tidak boleh bercanda, apalagi menertawakan orang lain."

(UdM, hlm. 58)

Dari kutipan cerita di atas, adanya aspek sosial pendidikan yang mengajarkan kita untuk saling menghargai sesama manusia bagaimanapun keadaannya.

Carpon "Katempuhan"

"Tah, geuning, salim ka Ua"

"Nah, uwa sudah datang, salam dulu."

(UdM, hlm. 66)

Kutipan cerita di atas, menggambarkan adanya aspek sosial yang mengajarkan tatakrama agar selalu bersikap hormat terhadap orang yang lebih dewasa.

\section{SIMPULAN}

Hasil analisis aspek sosial terbagi menjadi tiga bagian, yaitu aspek sosial agama, ekonomi, dan pendidikan.

Aspek sosial agama terdapat dalam lima judul cerpen. Indikator perilaku yang bisa dinilai adalah percaya kepada Alloh SWT terdapat dalam cerita "Paguneman". Indikator yang kedua adalah menjalankan perintah Alloh SWT terdapat dalam cerita "Usum Halodo Panjang", dan "Di Langit Béntang Baranang". Indikator yang ketiga adalah percaya kepada Alloh SWT serta belajar iklhas dan ridho yang terdapat dalam cerita "Surat keur Pusi", dan "Nganjang ka Sakola Luar Biasa".

Kumpulan cerita anak $U d M$ yang berkaitan dengan aspek sosial ekonomi terdapat dalam lima judul cerita. Yang menggambarkan kelas sosial ekonomi atas terdapat dalam cerita "Kanyaah Mamah", "Sang Raja", "Di Langit Béntang Baranang", dan "Katempuhan". Keadaan sosial ekonomi menengah ke atas terdapat dalam cerita "Si Centil Uky".

Aspek sosial pendidikan terdapat di delapan judul cerita anak $U d M$. Ada enam unsur dalam aspek sosial pendidikan, yang pertama adalah hormat kepada orang tua tergambar dalam cerita "Usum Halodo Panjang", "Di Langit Béntang Baranang", dan "Katempuhan". Unsur yang kedua adalah keluarga yang menjadi titik utama di dunia pendidikan yang terdapat dalam cerita "Kanyaah Mamah", dan "Sang Raja". Unsur yang ketiga adalah jangan iri dan dengki terdapat dalam kutipan cerita "Si Centil Uky". unsur yang keempat adalah rasa saling menghargai yang terdapat dalam cerita "Nganjang ka Sakola Luar Biasa". Unsur yang kelima adalah cinta tanah air terdapat dalam cerita "Ulin di Monumén". Dan unsur yang keenap adalah belajar mematuhi peraturan lalu lintas yang berlaku di masyarakat terdapat dalam cerita "Sang Raja".

\section{UCAPAN TERIMA KASIH}

Terima kasih kepada semua pihak yang telah membatu terselesaikannya artikel ini, terutama kepada kedua orang tua penulis, yang selalu mendo'akan dan memberi semangat, juga kepada Ibu Tetti Hodijah yang sudah menulis kumpulan cerita anak Ulin di Monumén, penulis ucapkan banyak terima kasih.

\section{CATATAN PENULIS}

Penulis menyatakan bahwa tidak ada konflik kepentingan terkait publikasi artikel ini. Penulis mengkonfirmasi bahwa data dan artikel ini bebas plagiarisme.

\section{PUSTAKA RUJUKAN}

Anwar, A. (2012). Teori Sosial Sastra. Yogyakarta: Penerbit Ombak.

Arikunto, S. (2013). Prosedur Penelitian Suatu Pendekatan Praktik. Jakarta: Rineka Cipta.

Djajasudarma, T. F. (2010). Ancangan

Metode Penelitian dan Kajian.

Bandung: Refika Aditama.

Hasanuddin, W. (2015). Sastra Anak. Bandung: Refika Aditama.

Hodijah, T. (2017). Ulin di Monumén. Bandung: Kiblat Buku Utama.

Kosasih, E. (2013). Sastra Klasik Sebagai 
$\begin{array}{lll}\text { Wahana } & \text { Efektif dalam } \\ \text { Pengembangan } & \text { Pendidikan } & \text { Karakter. }\end{array}$

Jurnal Pendidikan Bahasa dan

Sastra, $13 \quad$ (2), 225.

https://doi.org/10.17509/bs_jpbsp.v13 i2.294

Mulyana, Y. (2011). Pendidikan Sastra dan Karakter Bangsa. Bandung: Jurdiksatrasia FPBS UPI.

Sarumpaet, R. K. T. (2009). Pedoman Penelitian Sastra Anak. Jakarta: Pusat Bahasa Kementerian Pendidikan Nasional.
Suherman, A. (2019). Literacy Tradition of Sundanese Society - Indonesia: An annotation of the $16^{\text {th }}$ Century Ancient Manuscript. IJIER International Journal of Innovation of Education and Research, 7 (3), hlm. 262-271.

Suherman, A., \& Nugraha, H. S. (2019). Culture and Citizenship Literacy in Sundanese Children's Literature. 257(Icollite 2018), 346-348. https://doi.org/10.2991/icollite18.2019 .76 